\title{
Apple peel jejunal atresia
}

\author{
Arvind Navaneethkumar Viswanathan ${ }^{1}$, *Mohd Shahrulsalam Mohd Shah ${ }^{1}$, Norsuhana Omar ${ }^{2}$
}

Sri Lanka Journal of Child Health, 2021; 50(2): 362-364

DOI: http://dx.doi.org/10.4038/sljch.v50i2.9593

(Keywords: Atresia, apple peel, type III b, bubble shadows, intestinal obstruction)

\section{Introduction}

Intestinal atresia can be divided into atresia of the small and large intestine. Duodenal atresia has the highest incidence with figures of approximately 0.9 infants per 10,000 births $^{1}$. This is followed by jejunal/ileal atresia and the least common is colonic atresia, with a reported incidence of approximately 0.25 per 10,000 births $^{2}$. Our case is a rare type of intestinal atresia, the apple peel deformity. These babies are usually diagnosed antenatally, or suspected postnatally with features of abdominal distension and vomiting. Here we report such a case that was successfully diagnosed early and treated accordingly with excellent results.

\section{Case report}

A $2.82 \mathrm{~kg}$ non-syndromic baby was born to a 34 year-old lady, gravida 2, at 36 gestational weeks via spontaneous vaginal delivery. A detailed scan at 34 weeks of pregnancy showed signs of jejunal/ileal atresia. Clinically, the abdomen was not distended upon delivery and a nasogastric tube was inserted soon after birth. Abdominal radiograph showed the presence of bowel gas within the stomach, duodenum and jejunum giving the appearance of triple bubble sign, with an absence of bowel gas in the distal bowel loops and rectum (Figure 1).

The baby underwent an emergency exploratory laparotomy with findings of grossly dilated proximal jejunum which was $10 \mathrm{~cm}$ from duodenojejunal (DJ) junction and a type III b intestinal atresia, an Apple Peel type of deformity in the small bowel (Figure 2).

${ }^{1}$ Department of Surgery, ${ }^{2}$ Department of Physiology, School of Medical Sciences, Universiti Sains Malaysia, Kota Bahru, Kelantan, Malaysia, *Correspondence: shahrulsalam@usm.my

iD https://orcid.org/0000-0002-7540-6369

(Received on 06 January 20: Accepted after revision on 28 Febeuary 2020)

The authors declare that there are no conflicts of interest

Personal funding was used for the project.

Open Access Article published under the Creative Commons Attribution CC-BY (c) (i) License
An end-to-sside anastomosis was done without tapering enterostomy (Figure 3).

Postoperatively, the child was slow to tolerate feeds and thus, we proceeded with an upper gastrointestinal contrast study which showed free flow of contrast to the stomach, duodenum and proximal jejunum. However, no contrast was seen flowing past the anastomotic site, with a suspected diagnosis of anastomotic site stenosis (Figure 4).

Fortunately, repeated serial radiographs later showed the passage of contrast distally (Figure 5).

The child was treated conservatively and was able to establish feeds soon after. This baby was discharged on postoperative day 21 after attaining full feeds.

On subsequent follow-up, he has remained well with satisfactory weight gain.

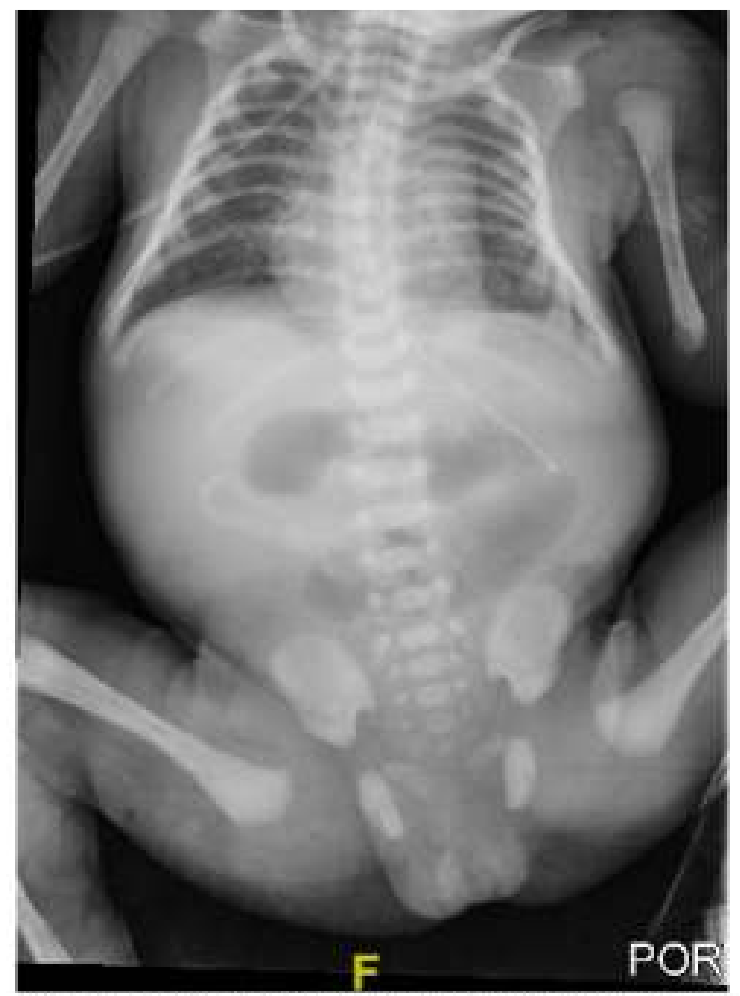

Figure 1: Triple bubble sign on abdominal $x$-ray 


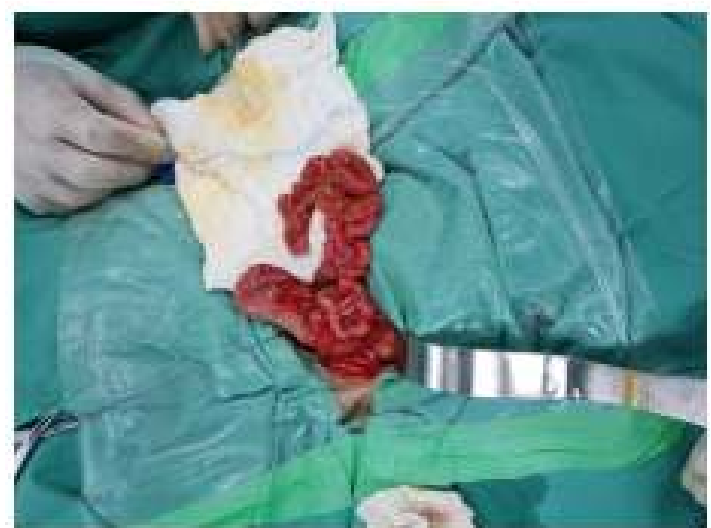

Figure 2: Intraoperative photograph showing apple peel atresia

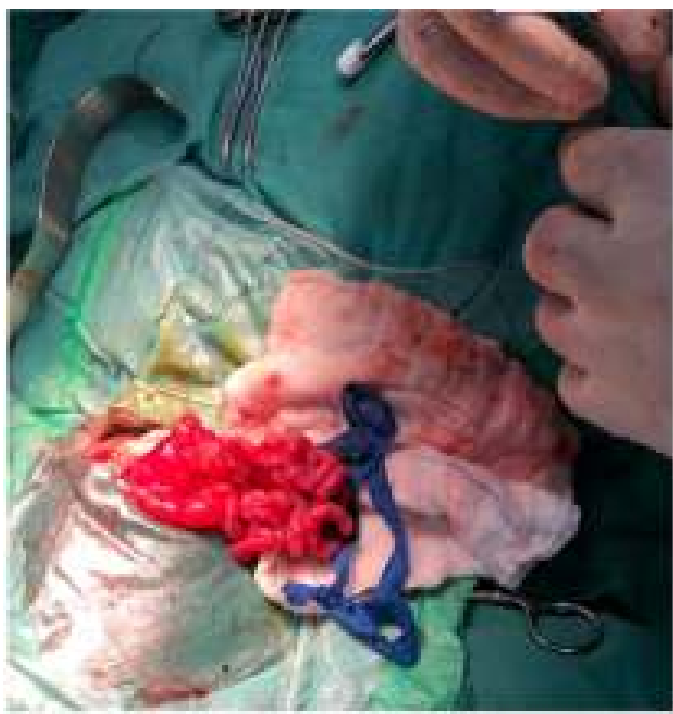

Figure 3: Intraoperative photograph shosing end-to-side anastomosis

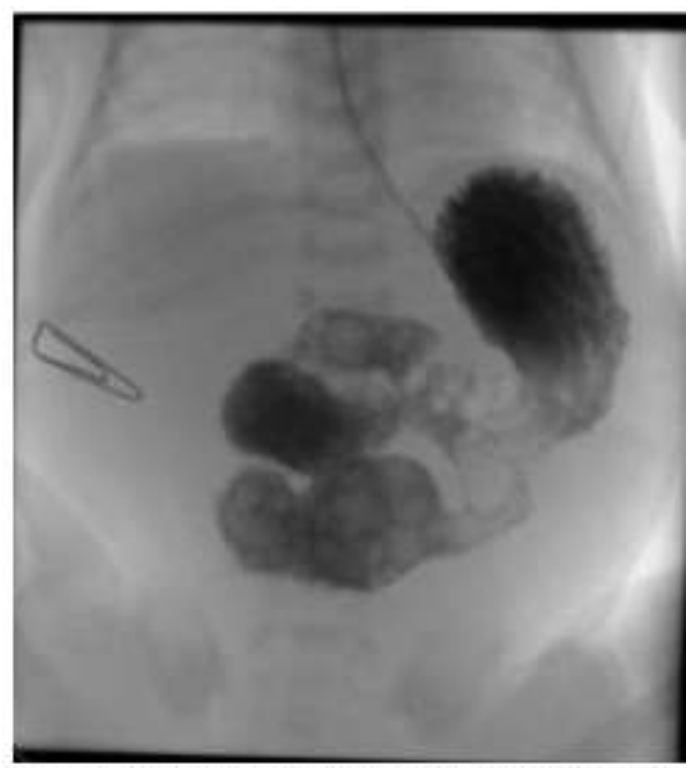

Figure 4: Upper gastrointestinal contrast study showing post-operative anastomotic stenosis

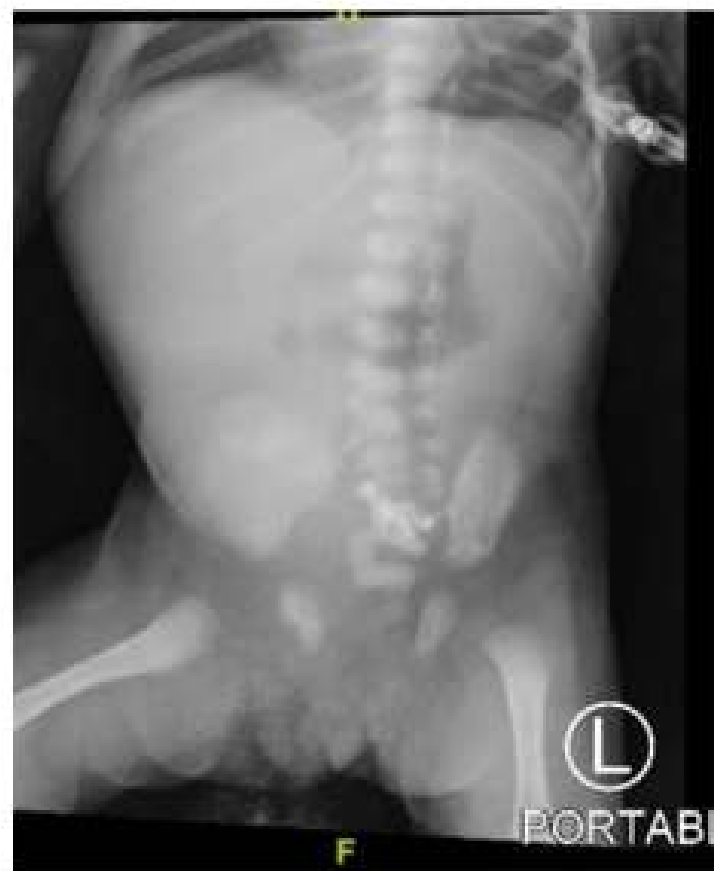

Figure 5: Abdominal x-ray showing contrast flowing through distally (rectum)

\section{Discussion}

Jejunal atresia with an apple peel deformity or apple peel atresia (APA) has an incidence of about 0.7 per 10,000 births ${ }^{1}$. The name 'apple peel' is due to the intraoperative appearance ${ }^{3}$. According to the Grosfeld modified Louw classification, type I has mucosal atresia, type II has two atretic ends connected by a fibrous band, type III has two atretic ends separated by mesenteric defect and type IV has multiple atresia ${ }^{3}$. Isolated cases of APA have a relatively poor outcome with values as high as $54 \%$ for the mortality rate ${ }^{4}$.

Clinically, upon delivery, one can be highly suspicious of APA if there are features of intestinal obstruction. Blood investigations may be unremarkable unless there is evidence of associated sepsis with raised inflammatory biomarkers like white blood cells or evidence of dehydration with raised urea or creatinine levels on renal profile.

Radiologically, prenatally on ultrasound, one can have a high index of suspicion if there is the presence of polyhydramnios, ascites, and dilated bowels. However, routine prenatal ultrasound has a low sensitivity in detecting gastrointestinal atresia and is incapable of accurately revealing the number and locations of atresia ${ }^{5}$. An abdominal radiograph can reveal the presence of dilated bowels with gas shadows up to the level of atresia. Other radiological modalities include upper gastrointestinal contrast studies and contrast enemas which can help exclude distal atresia ${ }^{6}$. 
The current surgical goal for this type of intestinal malformation is to maximize and preserve the intestinal peristaltic function while preventing short bowel syndrome ${ }^{7}$. Surgical techniques to correct intestinal atresia include resection with tapering enterostomy and anastomosis, resection with enterostomy or only enterostomy by primary resection, with end-to-oblique anastomosis ${ }^{8}$. In our case, we performed an end to side anastomosis without tapering enterostomy with satisfactory results, despite prior published data.

Complications associated with this condition include anastomotic leak, functional obstruction, sepsis, respiratory difficulties, short bowel syndrome, and malnutrition ${ }^{9}$. Late operative complications may consist of recurrent obstructions following anastomotic dysfunction, adhesions and strictures ${ }^{10}$. In our case, the baby initially had some functional obstruction which was treated with bowel rest and total parenteral nutrition.

\section{Acknowledgments}

We convey our acknowledgments to the director of Hospital Universiti Sains Malaysia, Professor Dato' Paduka Dr. Ahmad Sukari Halim.

\section{References}

1. Best KE, Tennant PWG, Addor M-C, Bianchi F, Boyd $\mathrm{P}$, Calzolari $\mathrm{E}$, et al. Epidemiology of small intestinal atresia in Europe: a register-based study. Archives of Disease in Childhood - Fetal and Neonatal Edition 2012; 97(5):F353-F8. https://doi.org/10.1136/fetalneonatal2011-300631

PMid:22933095

2. Adams SD, Stanton MP. Malrotation and intestinal atresias. Early Human Development 2014; 90(12): 921-5. https://doi.org/10.1016/j.earlhumdev.2014 .09.017

PMid:25448782

3. Dickson J. Apple peel small bowel: an uncommon variant of duodenal and jejunal atresia. Journal of Pediatric Surgery 1970; 5(6):595-600. https://doi.org/10.1016/S00223468(70)80 002-1

4. Alnosair AA, Naga MI, Abdulla MR, AlSalem AH. Congenital duodenal atresia with 'apple-peel configuration' of the small intestines and absent superior mesenteric artery: A case report and review of literature. Journal of Pediatric Surgery Case Reports 2014; 2(5):215-8. https://doi.org/10.1016/j.epsc.2014.02.005

5. Haeusler MC, Berghold A, Stoll C, Barisic I, Clementi M. Prenatal ultrasonographic detection of gastrointestinal obstruction: results from 18 European congenital anomaly registries. Prenatal diagnosis 2002; 22(7):616-23.

https://doi.org/10.1002/pd.341

PMid:12124699

6. Reid JR. Practical imaging approach to bowel obstruction in neonates: a review and update. Seminars in Roentgenology 2012; 47(1):21-31.

https://doi.org/10.1053/j.ro.2011.07.003

PMid:22166228

7. Rich BS, Bott M, Spigland N. Multiple intestinal atresia with apple peel syndrome successfully treated with primary repair. Journal of Pediatric Surgery Case Reports 2013; 1(7):157-9.

https://doi.org/10.1016/j.epsc.2013.05.015

8. Eltayeb AA. Different surgical techniques in management of small intestinal atresia in high risk neonates. Annals of Pediatric Surgery 2009; 5(1):31-5.

9. Stollman TH, de Blaauw I, Wijnen $\mathrm{MH}$, van der Staak FH, Rieu PN, Jos MT, et al. Decreased mortality but increased morbidity in neonates with jejunoileal atresia; a study of 114 cases over a 34year period. Journal of Pediatric Surgery 2009; 44(1):217-21.

https://doi.org/10.1016/j.jpedsurg.2008.10 .043

PMid: 19159746

10. Festen S, Brevoord JCD, Goldhoorn GA, Festen C, Hazebroek FWJ, van Heurn LWE, et al. Excellent long-term outcome for survivors of apple peel atresia. Journal of Pediatric Surgery 2002; 37(1):61-5. https://doi.org/10.1053/jpsu.2002.29428 PMid: 11781988 